\title{
Evaluating the effectiveness of using near-peer tutors in teaching first-year medical students
}

\author{
Authors: Ahmed Rashid, See Chai Chan, George Choa and Oziegbe Eboreime
}

\section{Introduction}

Innovation plays a major role in professions that require constant change and improvement, especially medicine. This is recognised by statutory bodies globally, yet research demonstrates that UK-based medical schools have not integrated the teaching of innovation as much as their US counterparts.

A recent example of innovative practice by medical schools is the introduction of near-peer teaching (NPT), where senior students teach junior students with the advantage of social and cognitive congruences. ${ }^{1}$ For junior students, NPT reportedly shows similar or better qualitative and quantitative outcomes than teaching by academics. ${ }^{2}$ For senior students, delivering NPT allows the development of greater proficiency in the topic and improvement of professional and communication skills. ${ }^{3}$

\section{Aim}

To establish effectiveness in using NPT to introduce medical innovation to first-year medical students.

\section{Methods}

Under the Student Selected Component scheme, three senior medical students led and delivered eight weekly sessions on topics of medical innovation, including education, technology and entrepreneurship.

Qualitative data from semi-structured focus group interviews, led by an academic, conducted on the near-peer tutors and first-year medical student tutees were coded and analysed thematically using NVivo. Structured evaluation questionnaires for tutees, completed at the end of the module, were also used to evaluate the effectiveness of the course.

\section{Results and Discussion}

Teaching sessions are currently ongoing, with formal data to be collected and analysed before the end of March.

Informal feedback shows that tutees recognise the importance of learning innovation to supplement their core curriculum. Tutees also appreciate being taught by near-peers, and report

Authors: University College London Medical School, London, UK development of transferable skills. Similarly, tutors describe greater confidence, improved teaching competence and increased understanding of the subject matter.

\section{Conclusion}

There is insufficient research to suggest negative implications of using NPT as a teaching method, especially on medical innovation. We believe that our findings on NPT will encourage senior students to take on teaching roles and prompt medical schools to support these endeavours.

\section{References}

1 Ten Cate O, Durning S. Peer teaching in medical education: twelve reasons to move from theory to practice. Med Teach 2007;29:591-9.

2 Ten Cate O, van de Vorst I, van den Broek S. Academic achievement of students tutored by near-peers. Int J Med Educ 2012;3:6-13.

3 Gregory A, Walker I, McLaughlin K, Peets AD. Both preparing to teach and teaching positively impact learning outcomes for peer teachers. Med Teach 2011;33:e417-22. 